\title{
Peridomestic Mammal Susceptibility to Severe Acute Respiratory Syndrome Coronavirus 2 Infection
}

\author{
Angela M. Bosco-Lauth, J. Jeffrey Root, Stephanie M. Porter, Audrey E. Walker, \\ Lauren Guilbert, Daphne Hawvermale, Aimee Pepper, Rachel M. Maison, \\ Airn E. Hartwig, Paul Gordy, Helle Bielefeldt-Ohmann, Richard A. Bowen
}

\begin{abstract}
Wild animals have been implicated as the origin of severe acute respiratory syndrome coronavirus 2 (SARS-CoV-2), but it is largely unknown how the virus affects most wildlife species and if wildlife could ultimately serve as a reservoir for maintaining the virus outside the human population. We show that several common peridomestic species, including deer mice, bushy-tailed woodrats, and striped skunks, are susceptible to infection and can shed the virus in respiratory secretions. In contrast, we demonstrate that cottontail rabbits, fox squirrels, Wyoming ground squirrels, black-tailed prairie dogs, house mice, and racoons are not susceptible to SARS-CoV-2 infection. Our results expand the knowledge base of susceptible species and provide evidence that human-wildlife interactions could result in continued transmission of SARS-CoV-2.
\end{abstract}

$\mathrm{T}$ he rapid global expansion of severe acute respiratory syndrome coronavirus 2 (SARS-CoV-2), which causes coronavirus disease (COVID-19), has been unprecedented in modern history. Although the original human infection(s) were potentially linked to wild animals in a wet market (1), humanto-human transmission is currently the dominant mechanism of viral spread. Peridomestic animals, which are represented by wild and feral animals living near humans, represent key species to evaluate for SARS-CoV-2 epidemiology for multiple reasons. First, given their common associations with humans and anthropogenically modified habitats, they represent the wildlife species with the greatest chance

Author affiliations: Colorado State University, Fort Collins, Colorado, USA (A.M. Bosco-Lauth, S.M. Porter, A.E. Walker,

L. Guilbert, D. Hawvermale, A. Pepper, R.M. Maison, A.E. Hartwig, P. Gordy, R.A. Bowen); US Department of Agriculture, Fort Collins (J.J. Root); The University of Queensland, St. Lucia, Queensland, Australia (H. Bielefeldt-Ohmann)

DOI: https://doi.org/10.3201/eid2708.210180 of exposure to the virus from humans (i.e., reverse zoonosis) or pets, such as cats. Second, should select peridomestic wildlife prove to be susceptible to the virus and have the capacity to replicate it to high viral titers, these species would have the potential to maintain the virus among conspecifics. Third, should some species possess the maintenance host criteria mentioned, they would represent wildlife species that would have the greatest chance (e.g., shedding ability and proximity to humans) to spread the virus back to humans. Wild rodents, cottontail rabbits (Sylvilagus sp.), raccoons (Procyon lotor), and striped skunks (Mephitis mephitis) can exhibit peridomestic tendencies in urban and suburban environments. Members of all those species/taxonomic groups have been shown to shed influenza A viruses after experimental inoculations (2-4), suggesting they might harbor productive infections when exposed to other human-pathogenic respiratory viruses.

Based upon protein analyses of amino acid residues of angiotensin-converting enzyme 2 (ACE2), transmembrane protease serine type 2, and spike protein, species susceptibility analyses suggested that, among other taxonomic groups, both carnivores and wild rodents are potentially high-risk groups (5-7). However, predicting susceptibility of specific species is more challenging. Looking at protein sequence analysis of ACE2 binding with the spike protein of SARS-CoV-2, one study indicated that raccoons could be ruled out as potential hosts for SARS-CoV-2 (6), and a different study based upon sequence analysis suggested that the western spotted skunks (Spilogale gracilis) had a low prediction of SARS-CoV-2 S binding propensity (7). Similarly, the same study also suggested that American mink (Neovison vison) have a similar prediction as western spotted skunks (7). However, over the past several months, outbreaks of SAR-CoV-2 in commercial mink farms have been 
reported in Europe and more recently in the United States $(8,9)$. Respiratory problems, rapid transmission, or unusually high mortality rates have been reported for this species in various regions $(8,10)$, which suggests that those analyses have limitations.

Because rodents are the largest and most diverse order of mammals, it is not surprising that the susceptibility of rodents to SARS-CoV-2 varies by species. To date, only a handful of rodent species have been evaluated as potential reservoir hosts or animal models for SARS-CoV-2, and the results largely indicate that outbred species, including laboratory animals, are at most only moderately affected. Most nontransgenic laboratory mice (Mus musculus) are resistant to infection, but transgenic humanized mice and hamsters, including Syrian hamsters (Mesocricetus auratus) and dwarf hamsters (Phodopus sp.), are highly susceptible $(11,12)$; 1 report described Roborovki dwarf hamsters becoming diseased and dying within 3 days of exposure (13). Other species, including deer mice (Peromyscus maniculatus), become infected and shed low titers of virus, but the infection is subclinical (A. Fagre, Colorado State University, pers. comm., 2020 Aug 7). Considering that there are $>1,700$ species of rodents worldwide, many of which exist closely at the human-wildlife interface, there remain many unanswered questions about SARSCoV-2 and wild rodents.

Various lagomorphs exist as pets, livestock, and peridomestic wildlife, and as such are in a prime position to come into contact with SARS-CoV-2-infected humans. In 1 study, New Zealand white rabbits were experimentally infected and shed infectious virus for $\leq 7$ days without signs of clinical disease (14). Wild rabbits, particularly cottontails in the United States, are prolific and commonly found around human dwellings, farms, and commercial buildings. Furthermore, as with rodents, wild rabbits are likely to be predated upon by domestic and wild felids and canids. Thus, the susceptibility of these animals must be determined to interpret the risk posed to them and by them from infection with SARS-CoV-2.

Among carnivores, felids and mustelids have been frequently linked to SARS-CoV-2 infections since the early stages of the pandemic. Domestic cats are highly susceptible to SARS-CoV-2 and are capable of transmitting the virus to other cats, suggesting that they could also potentially transmit virus to other animals $(15,16)$. Although striped skunks are currently considered to be mephitids, they are highly related to mammals within the family Mustelidae and were formerly classified as mustelids. Thus, on the basis of findings for SARS-CoV-2 susceptibility in various mustelids, we determined that the closely related mephitids are a logical candidate to evaluate for replication of this virus. Raccoons are notoriously associated with human environments and frequently interact with human trash and sewage; these interactions have been proposed as a potential indirect means for infected humans to transmit SARS-CoV-2 to mammalian wildlife (e.g., raccoons and select mustelids) (17-19). Thus, it is essential to determine the relative susceptibility of these common peridomestic carnivores and assess the likelihood that they could propagate infection.

In this study, we assessed 6 common peridomestic rodent species for susceptibility to SARS-CoV-2: deer mice, wild-caught house mice (Mus musculus), bushy-tailed woodrats (aka pack rats; Neotoma cinerea), fox squirrels (Sciurus niger), Wyoming ground squirrels (Urocitellus elegans), and black-tailed prairie dogs (Cynomys ludovicianus). These rodents are common in many parts of the United States, several of them frequently come into close contact with humans and human dwellings, and some are highly social animals, thus increasing the likelihood of pathogen transmission among conspecifics. In addition, we evaluated 3 other common peridomestic mammals: cottontail rabbits, raccoons, and striped skunks.

\section{Materials and Methods}

\section{Animals}

We evaluated the following mixed-sex animals for susceptibility to SARS-CoV-2: deer mice, house mice, bushy-tailed woodrats, Wyoming ground squirrels, black-tailed prairie dogs, fox squirrels, cottontail rabbits, striped skunks, and raccoons. Deer mice, house mice, and bushy-tailed woodrats were trapped by using Sherman traps (https://www.shermantraps.com) baited with grain. Wyoming ground squirrels, fox squirrels, black-tailed prairie dogs, and cottontails were trapped using Tomahawk live traps (https://www. livetrap.com) (e.g., 7 in $\times 7$ in $\times 20$ in or 7 in $\times 7$ in $\times 24$ in). All trapping was conducted in northern Colorado (Larimer, Jackson and Weld Counties) in accordance with Colorado wildlife regulations and with appropriate permits and Institutional Animal Care and Use Committee protocols in place. Skunks and raccoons were purchased from a private vendor. Animals were housed in an Animal Biosafety Level 3 facility at Colorado State University, in rooms $(12 \mathrm{ft} \times 18 \mathrm{ft})$ that had natural lighting and controlled climate. Mice, blacktailed prairie dogs, and Wyoming ground squirrels were group housed by species with access to water and food ad libitum. All other animals were housed individually with access to food and water ad libitum. 
Rodents were fed Teklad Rodent Diet (Enviro, https://www.envigo.com) supplemented with fresh fruit and occasional nuts. Rabbits were fed Manna Pro alfalfa pellets (https://www.mannapro.com) supplemented with grass hay and apples. Skunks and raccoons were fed Mazuri Omnivore Diet (https:// www. mazuri.com) supplemented with fresh fruit and occasional eggs. Raccoons, striped skunks, and black-tailed prairie dogs were implanted with thermally sensitive microchips (Bio-Thermo Lifechips, http://destronfering.com) for identification and temperature measurement and deer mice were ear notched; all other animals were identified by cage number or distinct markings.

\section{Virus}

We obtained SARS-CoV-2 strain WA1/2020WY96 from BEI Resources (https://www.beiresources.org), passaged it twice in Vero E6 cells, and prepared stocks frozen at $-80^{\circ} \mathrm{C}$ in Dulbecco modified Eagle medium containing $5 \%$ fetal bovine serum and antimicrobial drugs. We titrated the virus stock on Vero cells by using a standard double overlay plaque assay (15) and counted plaques 72 hours later to determine PFUs/mL.

\section{Virus Challenge}

Before challenge with SARS-CoV-2, we lightly anesthetized most animals as needed with $1-3 \mathrm{mg} / \mathrm{kg}$ xylazine and $10-30 \mathrm{mg} / \mathrm{kg}$ ketamine hydrochloride and collected a blood sample just before inoculation (day 0). We administered virus diluted in phosphatebuffered saline to all species into the nares by using a pipette $(50 \mu \mathrm{L}$ for deer and house mice, $100 \mu \mathrm{L}$ for bushy-tailed woodrats, and $200 \mu \mathrm{L}$ for all other species) and observed animals until they were fully recovered from anesthesia. Virus back-titration was performed on Vero cells immediately after inoculation, confirming that animals received $4.5-4.9 \log _{10}$ PFU of SARS-CoV-2.

\section{Sampling}

We used groups of 3 animals from each species (2 ground squirrels) for preliminary studies to evaluate viral shedding and acute pathologic changes. For these animals, we obtained oral swab specimens prechallenge and on days 1-3 postchallenge, at which time animals were euthanized and the following tissues harvested for virus isolation and formalin fixation: trachea, nasal turbinates, lung, heart, liver, spleen, kidney, small intestine, and olfactory bulb. The exception to this process was raccoons, for which we euthanized only 1 animal at day 3 ; we kept the remaining 2 raccoons through day 28 to evaluate serologic response. We swabbed the remaining 3-6 animals/selected species daily from days $0-5$ and 7 to further evaluate duration of viral shedding (if any). We sedated striped skunks and raccoons for all sampling and collected a nasal swab specimen in addition to the oral swab specimen. We evaluated tissues harvested from animals euthanized on day 7 as for the day 3 animals. We euthanized the remaining animals at 28 days postinfection (dpi), harvested tissues for histopathologic analysis, and collected serum for serologic analysis. We provide the necropsy scheme for each species (Table).

\section{Clinical Observations}

We clinically evaluated all animals daily and included assessment for temperament and any clinical signs of disease, such as ocular discharge, nasal discharge, ptyalism, coughing/sneezing, dyspnea, diarrhea, lethargy, anorexia, and moribund status. The stress of handling wild animals for sampling precluded the ability to obtain accurate body temperature measurements; as such, we excluded temperature in these preliminary studies for all species except skunks and raccoons, which were implanted with thermal microchips and could be measured under sedation during sampling.

\section{Viral Assays}

We performed plaque reduction neutralization assays as described (15). Serum samples were heatinactivated for $30 \mathrm{~min}$ at $56^{\circ} \mathrm{C}$, and 2-fold dilutions were prepared in Tris-buffered minimal essential

\begin{tabular}{lccc}
\hline \multicolumn{3}{l}{ Table. Wildlife species evaluated for experimental infections with SARS-CoV-2 and day animals were euthanized } \\
\hline Animals & No. euthanized at 3 dpi & No. euthanized at 7 dpi & No. euthanized at 28 dpi \\
\hline Deer mice, $\mathrm{n}=9$ & 3 & 3 & 3 \\
House mice, $\mathrm{n}=6$ & 3 & 0 & 3 \\
Bushy-tailed woodrats, $\mathrm{n}=6$ & 3 & 0 & 3 \\
Fox squirrels, $\mathrm{n}=3$ & 3 & 0 & 0 \\
Wyoming ground squirrels, $\mathrm{n}=2$ & 2 & 0 & 0 \\
Black-tailed prairie dogs, $\mathrm{n}=9$ & 3 & 3 & 3 \\
Cottontails, $\mathrm{n}=3$ & 3 & 0 & 0 \\
Raccoons, $\mathrm{n}=3$ & 1 & 0 & 2 \\
Striped skunks, $\mathrm{n}=6$ & 3 & 0 & 3 \\
\hline
\end{tabular}

*dpi, days postinfection; SARS-CoV-2, severe acute respiratory syndrome coronavirus 2 . 
medium containing $1 \%$ bovine serum albumin starting at a 1:5 dilution and aliquoted onto 96-well plates. An equal volume of virus was added to the serum dilutions and incubated for 1 hour at $37^{\circ} \mathrm{C}$. After incubation, serum-virus mixtures were plated onto Vero monolayers as described for virus isolation assays. We screened serum samples for antibodies specific to SARS-CoV-2 to ensure seronegative status before inoculation by using a cutoff value $<50 \%$ viral neutralization. We recorded antibody titers as the reciprocal of the highest dilution in which $>90 \%$ of virus was neutralized.

\section{Serologic Analysis}

We performed plaque reduction neutralization assays as described (15). We heat-inactivated serum samples for $30 \mathrm{~min}$ at $56^{\circ} \mathrm{C}$, and prepared 2-fold dilutions in Tris-buffered minimal essential medium containing $1 \%$ bovine serum albumin starting at a 1:5 dilution and aliquoted onto 96-well plates. We added an equal volume of virus to the serum dilutions and incubated the serum dilutions for 1 hour at $37^{\circ} \mathrm{C}$. After incubation, we plated serum-virus mixtures onto Vero monolayers as described for virus isolation assays. We screened serum samples for antibodies specific to SARS-CoV-2 to ensure seronegative status before inoculation by using a cutoff value $<50 \%$ viral neutralization. We recorded antibody titers as the reciprocal of the highest dilution in which $>90 \%$ of virus was neutralized.

\section{Quantitative Reverse Transcription PCR}

We picked plaques from culture plates from each positive animal to confirm SARS-CoV-2 viral shedding. We extracted RNA by using QiaAmp Viral RNA Mini Kits (QIAGEN, https://www.qiagen. com) according to the manufacturer's instructions. We performed reverse transcription PCR (RT-PCR) by using the E_Sarbeco primer probe sequence described by Corman et al. (20) and the Superscript III Platinum One-Step qRT-PCR System (Invitrogen, https://www.thermofisher.com) with the following modification: the initial reverse transcription was at $50^{\circ} \mathrm{C}$. RNA standards for PCR were obtained from BEI Resources.

\section{Histopathologic Analysis}

We fixed animal tissues in 10\% neutral-buffered formalin for 12 days and transferred them to $70 \%$ ethanol before processing for paraffin embedding and sectioning for staining with hematoxylin and eosin. Slides were read by a veterinary pathologist blinded to the treatments.

\section{Results}

\section{Viral Shedding}

Of the 9 species evaluated, 3 (deer mice, bushy-tailed woodrats, and striped skunks) shed infectious virus after challenge (Figure). Deer mice, which have previously been demonstrated to shed infectious SARSCoV-2 experimentally (A. Fagre, Colorado State University, pers. comm., 2020 Aug 7), shed virus orally for $\leq 4$ days and virus was isolated from lungs $(3 / 3)$ and trachea (2/3) of animals tested at 3 dpi. All 9 inoculated deer mice shed virus on at $\geq 2$ of the first 4 days after infection and had peak titers of $3.1 \log _{10}$ $\mathrm{PFU} /$ swab specimen. Bushy-tailed woodrats shed virus orally for $\leq 5$ days postinoculation $(6 / 6)$, and virus was isolated from turbinates $(2 / 3)$, trachea $(1 / 3)$, and lung $(1 / 3)$ from animals that underwent necropsy on 3 dpi. Peak titers from bushy-tailed woodrats reached $3.0 \log _{10}$ PFU/swab specimen 3 dpi. The single bushytailed woodrat for which infectious virus was isolated from the lungs only shed $1.3 \log _{10}$ PFU/swab specimen orally on the day of necropsy, but the lungs contained $5.2 \log _{10} \mathrm{PFU} / \mathrm{g}$ of virus.

Striped skunks, which had to be handled under heavy sedation, were sampled on days $1-3,5$, and 7 , during which time 3 of the 6 infected animals shed virus orally, nasally, or both, and 1 animal shed $\leq 7$ dpi. Of the 3 skunks that underwent necropsy on 3 dpi, 2 had infectious virus in the turbinates but not in other tissues tested. One of those 2 animals had $3.2 \log _{10} \mathrm{PFU} / \mathrm{g}$ of virus in the turbinates but did not shed detectable virus nasally or orally before euthanasia. In general, viral titers were slightly higher in nasal samples than oral samples, but overall peak titers in skunks were relatively low, with oral titers reaching $2 \log _{10} \mathrm{PFU} / \mathrm{swab}$ specimen and nasal titers reaching $2.3 \log _{10} \mathrm{PFU} /$ swab specimen. All animals that had plaque assay-positive samples were confirmed as having SARS-CoV-2 by RT-PCR. Similarly, all animals that were negative by plaque assay were confirmed as negative for viral shedding by RT-PCR.

\section{Seroconversion}

All animals were seronegative against SARS-CoV-2 at the time of inoculation. On the basis of the lack of evidence of infection and the overall difficulty of maintaining wildlife, we opted not to hold subsets of squirrels or rabbits for additional time to assess seroconversion. We assessed neutralizing antibody titers in all animals euthanized at $28 \mathrm{dpi}$, which included deer mice, house mice, bushy-tailed woodrats, blacktailed prairie dogs, raccoons, and striped skunks. All species that had detectable viral infections (deer 

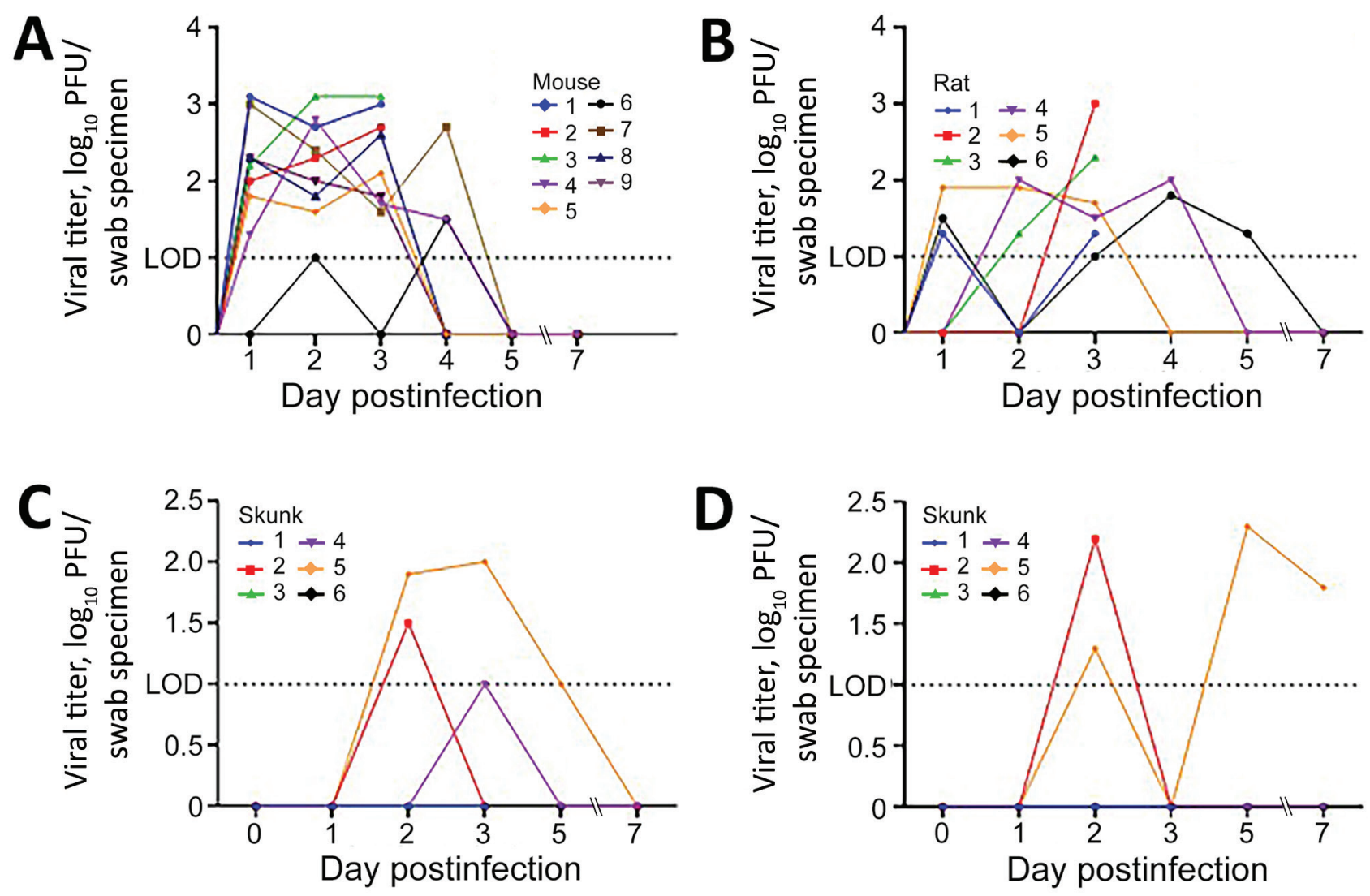

Figure. Oropharyngeal shedding of severe acute respiratory syndrome coronavirus 2 in deer mice (A), bushy-tailed woodrats (B), and striped skunks (C) and nasal shedding in striped skunks (D). LOD $=1 \log _{10} P F U$. LOD, limit of detection.

mice, skunks, and bushy-tailed woodrats) also had neutralizing antibodies develop, whereas the other species (house mice, raccoons, and black-tailed prairie dogs) did not. Deer mice and bushy-tailed woodrats reached or exceeded titers of 1:80, the 2 skunks that shed infectious virus reached or exceeded titers of 1:160, and the single skunk that did not shed virus had a titer of $1: 10$ at $28 \mathrm{dpi}$. We did not test animals euthanized at 3 dpi for seroconversion because previous investigations have demonstrated that neutralizing antibodies are typically not detectable during acute infection (21).

\section{Clinical Disease}

None of the animals exhibited clinical signs of disease (see Materials and Methods) at any time during the study. Skunks and raccoons, which were sedated for sampling procedures, did not display increased elevated temperatures at those times. In addition to monitoring clinical signs, we monitored behavior by observing animals through double-paned glass and assessing eating and response to provided enrichment (playing with toys, eating treats, using hides).
None of the animals behaved abnormally after infection compared with the acclimation period.

\section{Pathology}

None of the animals had gross lesions at the time of necropsy. At histopathologic examination of tissues harvested $3 \mathrm{dpi}$, rare, small foci of mild macrophage and neutrophil infiltration were noted in the lungs of 2 woodrats and 2 deer mice with one of the deer mice also having mild vasculitis. Two skunks had welldeveloped bronchioles associated lymphoid tissue, but inflammation was not apparent in the lungs or other tissues.

\section{Discussion}

COVID-19 has had a major impact on the human population globally, but so far little is known about how SARS-CoV-2 virus affects wildlife. Domestic cats and dogs have repeatedly been shown to be infected by SARS-CoV-2, but with few exceptions these infections are subclinical or animals show development of mild clinical disease $(15,22,23)$. Conversely, farmed mink are not only susceptible 
to infection but can also have fulminating fatal disease develop $(10,24)$. In contrast, ferrets, which are closely related to mink, shed virus after infection, but the infection is subclinical (25). Raccoon dogs, which were heavily implicated in the severe acute respiratory syndrome outbreak during 2002-2004, are susceptible to SARS-CoV-2 infection, but infections remain subclinical (26). Experimentally, deer mice can be infected and shed the virus by oral secretions, as demonstrated by this study and others (A. Fagre, Colorado State University, pers. comm., 2020 Aug 7). However, other mice, including wild house mice and nontransgenic laboratory strains of this species, are not susceptible to infection by SARS-CoV-2 (27).

Studies in which bats and select small mammals were experimentally exposed to SARS-CoV-2 showed that some species (i.e., fruit bats [Rousettus aegyptiacus] and tree shrews [Tupaia belangeri]) are capable of minimal viral replication, but others (big brown bats [Eptesicus fuscus]) do not become infected, which suggests that although the virus might have originated in bats, they are unlikely to serve as reservoir hosts (28-30). The confounding clinical response to infection between closely related species makes predicting impacts on wildlife and their potential for reservoir maintenance difficult. Despite best attempts to predict host susceptibility on the basis of receptor similarity or other modeling approaches, experimental infections remain the standard for evaluating the susceptibility of an animal to infection and following the course of disease.

Our results demonstrate that several common peridomestic wildlife species, including deer mice, bushy-tailed woodrats, and striped skunks, are susceptible to SARS-CoV-2 infection and can shed infectious virus. Our results and the results of others indicate that so far, most exposed wildlife species show development of mild to no clinical disease and either did not shed virus or shed low levels for short durations $(26,28-30)$. These experimental infections suggest that we can rule out several common rodents, selected wild lagomorphs, and raccoons as potential SARS-CoV-2 reservoirs. However, there are limitations to these experimental models, namely that the animals in our studies were directly exposed to high doses (e.g., $5 \log _{10}$ PFU) of virus, which is unlikely to be representative of an exposure in nature. In addition, experimental infections using low numbers of apparently healthy, immunocompetent animals do not generate sufficient data to fully characterize the risk posed to animals of varying ages and health status. However, results of this study and results of others, combined with the dramatic response to infection seen in certain species, such as mink, indicate that SARS-CoV-2 might infect infecting wildlife, establishing a transmission cycle, and becoming endemic in nonhuman species. In particular, the relatively high titers observed in select woodrat tissues (e.g., $5.2 \log _{10} \mathrm{PFU} / \mathrm{g}$ of lung) suggests that a predator-prey transmission scenario among this rodent species and various small wild and domestic carnivore species is plausible, and experiments designed to capture oral transmission between prey and predator are a logical next step in determining the likelihood of this scenario.

The major outcomes of such an event include direct threat to the health of wildlife and establishment of a reservoir host, which could complicate control measures of this virus in human populations. Experimental studies to identify and characterize responses of species to SARS-CoV-2 infection help scientists classify those species that are at highest risk and enable implementation of prevention measures. For example, because deer mice and bushy-tailed woodrats are commonly found in barns and sheds near humans, when cleaning out sheds or attempting to rodent-proof barns, persons should consider wearing appropriate personal protective equipment to prevent exposure to the pathogens that rodents carry, as well as to prevent exposing wildlife to SARS-CoV-2. Persons whose occupations put them in contact with susceptible animals (biologists, veterinarians, rehabilitators) and COVID-19 patients who own cats and dogs should practice extra precaution when interacting with animals, including minimizing their pet's exposure to wildlife. Of note, a photo-monitoring study provided evidence that striped skunks can commonly use the same urban cover types (e.g., outbuildings and decks) as domestic cats (31). Intentionally available pet food and spilled bird feed, which were 2 of the attractants evaluated, produced instances where skunks and domestic cats were documented to be on study sites simultaneously or nearly simultaneously, which could lead to interspecies transmission of SARS-CoV-2.

Wildlife and SARS-CoV-2 are intricately involved, from the initial spillover event to potential reverse zoonotic transmission, and we will undoubtedly continue to discover more susceptible species as the search for zoonotic reservoirs continues. COVID-19 is just the latest in a series of examples of how the human-wildlife interface continues to drive the emergence of infectious disease. Using experimental research, field studies, surveillance, genomics, and modeling as tools for predicting outbreaks and epidemics should help provide the knowledge base and resources necessary to prevent future pandemics. 
This study was supported by internal funding from Colorado State University and the US Department of Agriculture, Animal and Plant Health Inspection Service. A.E.W. and L.G. were supported by the US Department of Agriculture Animal Health and Disease Veterinary Summer Scholars Program.

\section{About the Author}

Dr. Bosco-Lauth is an assistant professor in the Department of Biomedical Sciences, Colorado State University. Fort Collins, CO. Her research interests include pathogenesis, transmission, and ecology of infectious diseases.

\section{References}

1. Zhou P, Yang X-L, Wang X-G, Hu B, Zhang L, Zhang W, et al. A pneumonia outbreak associated with a new coronavirus of probable bat origin. Nature. 2020;579:270-3. https:// doi.org/10.1038/s41586-020-2012-7

2. Root JJ, Bosco-Lauth AM, Bielefeldt-Ohmann H, Bowen RA. Experimental infection of peridomestic mammals with emergent H7N9 (A/Anhui/1/2013) influenza A virus: implications for biosecurity and wet markets. Virology. 2016;487:242-8. https:/ / doi.org/10.1016/j.virol.2015.10.020

3. Shriner SA, VanDalen KK, Mooers NL, Ellis JW, Sullivan HJ, Root JJ, et al. Low-pathogenic avian influenza viruses in wild house mice. PLoS One. 2012;7:e39206. https:// doi.org/ 10.1371/journal.pone.0039206

4. Romero Tejeda A, Aiello R, Salomoni A, Berton V, Vascellari M, Cattoli G. Susceptibility to and transmission of H5N1 and H7N1 highly pathogenic avian influenza viruses in bank voles (Myodes glareolus). Vet Res (Faisalabad). 2015;46:51. https:/ / doi.org/10.1186/s13567-015-0184-1

5. Martínez-Hernández $F$, Isaak-Delgado AB, Alfonso-Toledo JA, Muñoz-García CI, Villalobos G, Aréchiga-Ceballos N, et al. Assessing the SARS-CoV-2 threat to wildlife: potential risk to a broad range of mammals. Perspect Ecol Conserv. 2020;18:223-34. https://doi.org/10.1016/j.pecon.2020.09.008

6. Luan J, Lu Y, Jin X, Zhang L. Spike protein recognition of mammalian ACE2 predicts the host range and an optimized ACE2 for SARS-CoV-2 infection. Biochem Biophys Res Commun. 2020;526:165-9. https:// doi.org/10.1016/ j.bbrc.2020.03.047

7. Damas J, Hughes GM, Keough KC, Painter CA, Persky NS, Corbo M, et al. Broad host range of SARS-CoV-2 predicted by comparative and structural analysis of ACE2 in vertebrates. Proc Natl Acad Sci U S A. 2020;117:22311-22. https://doi.org/10.1073/pnas.2010146117

8. Oreshkova N, Molenaar RJ, Vreman S, Harders F, Oude Munnink BB, Hakze-van der Honing RW, et al. SARS-CoV-2 infection in farmed minks, the Netherlands, April and May 2020. Euro Surveill. 2020;25. https:/ / doi.org/10.2807/ 1560-7917.ES.2020.25.23.2001005

9. Shriner SA, Ellis JW, Root JJ, Roug A, Stopak SR, Wiscomb GW, et al. SARS-CoV-2 exposure in escaped mink, Utah, USA. Emerg Infect Dis. 2021;27:988-90. https:// doi.org/10.3201/ eid2703.204444

10. Molenaar RJ, Vreman S, Hakze-van der Honing RW, Zwart R, de Rond J, Weesendorp E, et al. Clinical and pathological findings in SARS-CoV-2 disease outbreaks in farmed mink (Neovison vison). Vet Pathol. 2020;57:653-7. https:/ / doi.org/10.1177/0300985820943535
11. Younes S, Younes N, Shurrab F, Nasrallah GK. Severe acute respiratory syndrome coronavirus-2 natural animal reservoirs and experimental models: systematic review. Rev Med Virol. 2020;Nov 18:e2196.

12. Sia SF, Yan LM, Chin AW, Fung K, Choy KT, Wong AYL, et al. Pathogenesis and transmission of SARS-CoV-2 in golden hamsters. Nature. 2020;583:834-8. https:// doi.org/ 10.1038/s41586-020-2342-5

13. Trimpert J, Vladimirova D, Dietert K, Abdelgawad A, Kunec D, Dökel S, et al. The Roborovski dwarf hamster is a highly susceptible model for a rapid and fatal course of SARS-CoV-2 infection. Cell Rep. 2020;33:108488. https://doi.org/10.1016/j.celrep.2020.108488

14. Mykytyn AZ, Lamers MM, Okba NM, Breugem TI, Schipper D, van den Doel PB, et al. Susceptibility of rabbits to SARS-CoV-2. Emerg Microbes Infect. 2021;10:1-7. https:/ / doi.org/10.1080/22221751.2020.1868951

15. Bosco-Lauth AM, Hartwig AE, Porter SM, Gordy PW, Nehring M, Byas AD, et al. Experimental infection of domestic dogs and cats with SARS-CoV-2: Pathogenesis, transmission, and response to reexposure in cats. Proc Natl Acad Sci U S A. 2020;117:26382-8. https:/ / doi.org/10.1073/ pnas. 2013102117

16. Shi J, Wen Z, Zhong G, Yang H, Wang C, Huang B, et al. Susceptibility of ferrets, cats, dogs, and other domesticated animals to SARS-coronavirus 2. Science. 2020;368:1016-20. https://doi.org/10.1126/science.abb7015

17. Gross J, Elvinger F, Hungerford LL, Gehrt SD. Raccoon use of the urban matrix in the Baltimore Metropolitan Area, Maryland. Urban Ecosyst. 2012;15:667-82. https:/ / doi.org/ 10.1007/s11252-011-0218-z

18. Hoffmann CO, Gottschang JL. Numbers, distribution, and movements of a raccoon population in a suburban residential community. J Mammal. 1977;58:623-36. https:// doi.org/10.2307/1380010

19. Franklin AB, Bevins SN. Spillover of SARS-CoV-2 into novel wild hosts in North America: a conceptual model for perpetuation of the pathogen. Sci Total Environ. 2020 ;733:139358. https:// doi.org/10.1016/j.scitotenv. 2020.139358

20. Corman VM, Landt O, Kaiser M, Molenkamp R, Meijer A, Chu DK, et al. Detection of 2019 novel coronavirus (2019-nCoV) by real-time RT-PCR. Euro Surveill. 2020;25. https:// doi.org/10.2807/1560-7917.ES.2020.25.3.2000045

21. Kellam P, Barclay W. The dynamics of humoral immune responses following SARS-CoV-2 infection and the potential for reinfection. J Gen Virol. 2020;101:791-7. https:/ / doi.org/ 10.1099/jgv.0.001439

22. Patterson EI, Elia G, Grassi A, Giordano A, Desario C, Medardo M, et al. Evidence of exposure to SARS-CoV-2 in cats and dogs from households in Italy. Nat Commun. 2020;11:6231. https:/ / doi.org/10.1038/s41467-020-20097-0

23. de Morais HA, Dos Santos AP, do Nascimento NC, Kmetiuk LB, Barbosa DS, Brandão PE, et al. Natural infection by SARS-CoV-2 in companion animals: a review of case reports and current evidence of their role in the epidemiology of COVID-19. Front Vet Sci. 2020;7:591216. https://doi.org/10.3389/fvets.2020.591216

24. Hammer AS, Quaade ML, Rasmussen TB, Fonager J, Rasmussen M, Mundbjerg K, et al. SARS-CoV-2 transmission between mink (Neovison vison) and humans, Denmark. Emerg Infect Dis. 2021;27:547-51. https:/ / doi.org/ 10.3201/eid2702.203794

25. Kim Y-I, Kim S-G, Kim S-M, Kim E-H, Park S-J, Yu K-M, et al. Infection and rapid transmission of SARS-CoV-2 in ferrets. Cell Host Microbe. 2020;27:704-709.e2. https:/ / doi.org/10.1016/j.chom.2020.03.023 
26. Freuling CM, Breithaupt A, Müller T, Sehl J, BalkemaBuschmann A, Rissmann M, et al. Susceptibility of raccoon dogs for experimental SARS-CoV-2 infection. Emerg Infect Dis. 2020;26:2982-5. https:// doi.org/10.3201/ eid2612.203733

27. Cohen J. From mice to monkeys, animals studied for coronavirus answers. Science. 2020;368:221-2. https:/ / doi.org/ 10.1126/science.368.6488.221

28. Hall JS, Knowles S, Nashold SW, Ip HS, Leon AE, Rocke T, et al. Experimental challenge of a North American bat species, big brown bat (Eptesicus fuscus), with SARS-CoV-2. Transbound Emerg Dis. 2020;Dec 9:tbed.13949. https://doi.org/10.1111/tbed.13949

29. Schlottau K, Rissmann M, Graaf A, Schön J, Sehl J, Wylezich C, et al. SARS-CoV-2 in fruit bats, ferrets, pigs, and chickens: an experimental transmission study. Lancet Microbe. 2020;1:e21825. https://doi.org/10.1016/S2666-5247(20)30089-6
30. Zhao Y, Wang J, Kuang D, Xu J, Yang M, Ma C, et al. Susceptibility of tree shrew to SARS-CoV-2 infection. Sci Rep. 2020;10:16007. https://doi.org/10.1038/ s41598-020-72563-w

31. Weissinger MD, Theimer TC, Bergman DL, Deliberto TJ. Nightly and seasonal movements, seasonal home range, and focal location photo-monitoring of urban striped skunks (Mephitis mephitis): implications for rabies transmission. J Wildl Dis. 2009;45:388-97. https://doi.org/10.7589/ 0090-3558-45.2.388

Address for correspondence: Angela Bosco-Lauth, Department of Biomedical Sciences, Colorado State University, 1683 Campus Delivery, Fort Collins, CO 80523, USA; email: angela.bosco-lauth@colostate.edu

\section{The Public Health Image Library}
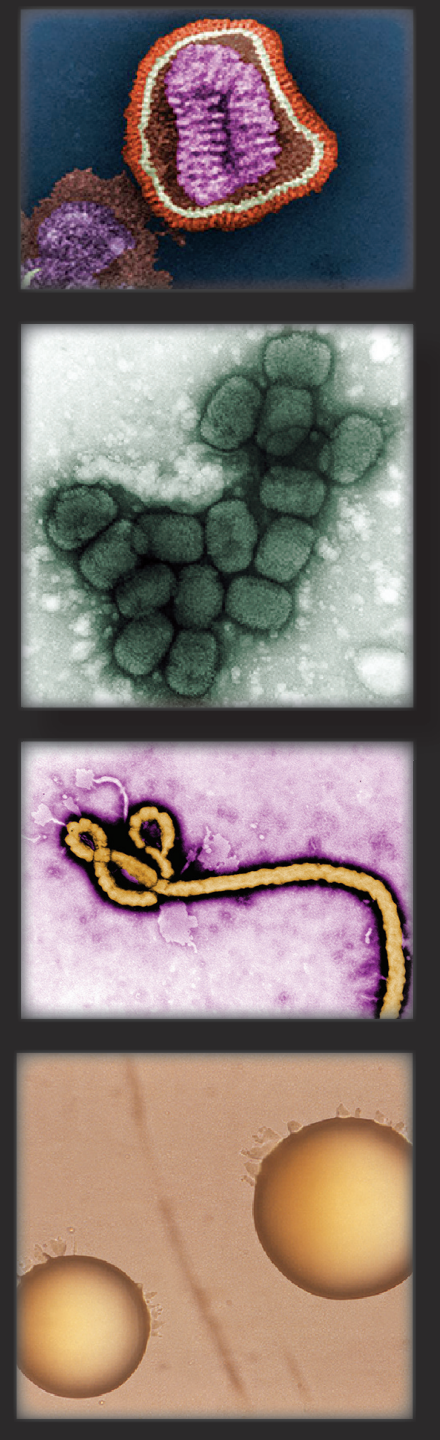
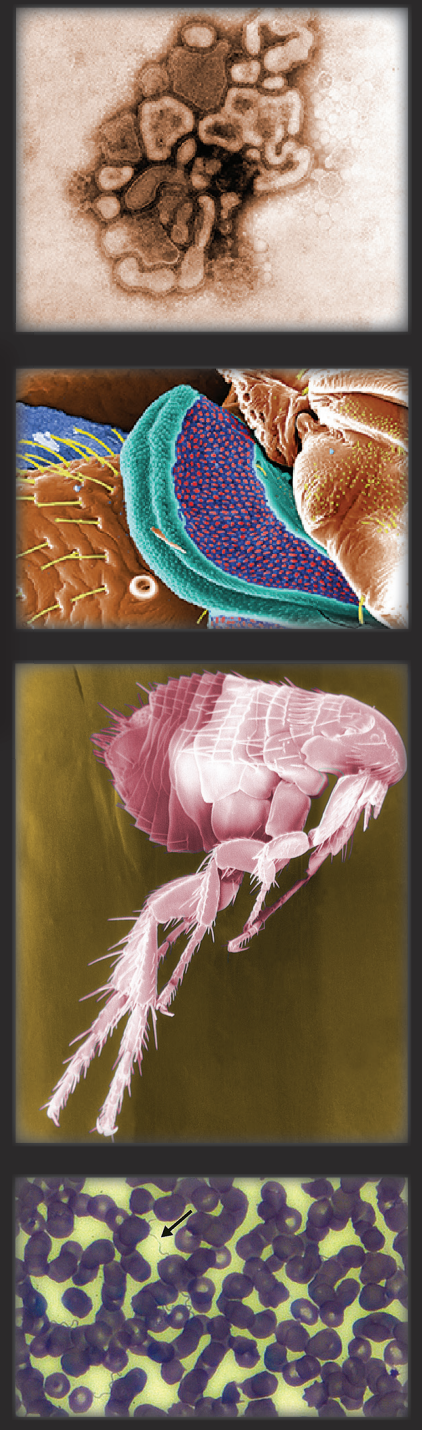

The Public Health Image Library (PHIL), Centers for Disease Control and Prevention, contains thousands of public health-related images, including highresolution (print quality) photographs, illustrations, and videos.

PHIL collections illustrate current events and articles, supply visual content for health promotion brochures, document the effects of disease, and enhance instructional media.

PHIL images, accessible to PC and Macintosh users, are in the public domain and available without charge.

Visit PHIL at: http: / /phil.cdc.gov/phil 